\title{
La organización sindical de los trabajadores agrarios en Uruguay: origen, trayectoria y perspectivas
}

The union organization of agrarian workers in Uruguay: origin, trajectory and perspectives

\author{
Alberto Riella \\ Universidad de la República, Uruguay \\ albertoriella@gmail.com \\ Paola Mascheroni \\ Universidad de la República, Uruguay \\ paola.mascheroni@cienciassociales.edu.uy
}

\section{ReSUMEN:}

Los asalariados agrarios de Uruguay han presentado históricamente un rezago en sus derechos laborales y en su organización sindical. El propósito del artículo es reflexionar sobre la situación actual del sindicalismo agrario en un escenario político de expansión y reconocimiento de los derechos laborales de los asalariados y de apertura de la negociación colectiva en el sector. Con este fin se desarrollan analíticamente las distintas experiencias organizativas de los asalariados agrarios y su significación para la acción colectiva de estos trabajadores en el país. Luego se discuten los elementos de carácter más permanente que obstaculizan su sindicalización. Finalmente, se argumenta que a pesar de las peculiaridades del contexto histórico para la aplicabilidad de sus derechos laborales, el movimiento sindical rural no ha logrado consolidarse.

PALABRas ClaVE: Asalariados agrarios, Sindicalismo, Trabajo rural, Uruguay.

\section{Abstract:}

The uruguayan rural workers have historically presented a backlog in their labor rights and inside their trade union movement. The purpose of this article is to reflect on the present situation of rural workers trade unions in a political scenario of expansion and recognition of workers' rights and the opening of collective bargaining. First, we examine the different organizational experiences of rural workers and the significance for their collective actions. Then, the more permanent elements that hinder their unionization are discussed. Finally, we argue that despite the peculiarities of the historical context for the applicability of their labor rights, the rural trade union movement has not been able to consolidate.

KEYwORDs: Agrarian workers, Trade unionism, Rural work, Uruguay.

\section{INTRODUCCIÓN}

El sector agropecuario uruguayo se caracteriza por su temprana asalarización ${ }^{1}$ en relación a otros países de la región, y hasta el día de hoy los asalariados representan la principal fuerza de trabajo en el agro. Pero estos sujetos vitales para la producción nacional han sufrido una falta histórica en el otorgamiento de sus derechos laborales y ciudadanos, y constituyen uno de los grupos más vulnerables del país. A su vez, su capacidad de organización colectiva ha sido muy limitada, mostrando, salvo excepciones, niveles de sindicalización muy bajos. ${ }^{2}$ En consecuencia, se produce el "olvido y ocultamiento" de los trabajadores rurales en la sociedad uruguaya, y la ausencia de reconocimiento de sus organizaciones sociales (Latorre, 1986, 1991, 1993a y 1993b; Rocha, 1991 y 2008; González Sierra, 1994).

Los autores que han estudiado el sindicalismo rural en Uruguay han expuesto de diferentes formas lo que puede considerarse como trabas o limitantes para estos procesos colectivos. Algunas de ellas son comunes al desarrollo de las actividades sindicales en el país, y otras, más específicas, refieren a los problemas que enfrenta 
el trabajador rural para el desarrollo de organizaciones que promuevan y defiendan sus derechos laborales. Estas dificultades para el desarrollo del sindicalismo pueden agruparse en tres grandes componentes.

El primer grupo de factores se vincula las relaciones socio políticas imperantes en el agro. En este aspecto se ubican aquellas consideraciones que hacen referencia a las construcciones hegemónicas, las relaciones de poder entre los actores y su vinculación con las representaciones del mundo, los procesos identitarios, culturales y simbólicos referidos a la "atmósfera cultural rural" (Moreira, 2010).

En este campo de poder se enfrentan dos grupos sociales que se ubican en las antípodas: por un lado los estancieros y empresarios rurales, uno de los grupos con mayor poder económico y simbólico de la sociedad uruguaya, y por otro los asalariados, uno de los sectores más vulnerables del país. Las clases agrarias dominantes, en especial las organizaciones de los estancieros, se opusieron sistemáticamente a las organizaciones sindicales en el campo (Riella, 2006).

La imposición de una visión del mundo rural que coloca el eje del conflicto entre el campo y la ciudad, impide la conformación de una conciencia de clase al eliminar simbólicamente los conflictos entre el capital y el trabajo (Latorre, 1991; Riella, 2006; Mascheroni, 2011). El vínculo cotidiano y cercano que se establece con los empresarios y que dificulta establecer la línea divisoria entre patrones y asalariados, particularmente en los casos de productores familiares o cuando se da un trato cotidiano con capataces o jefes de cuadrilla, inhibe los intentos de participación sindical (Rocha, 1991).

También el control social y el disciplinamiento de los trabajadores mediante el sistema de contratación que privilegia a los "buenos" trabajadores sobre los “problemáticos”- desalientan la sindicalización (Moreira, 2010). Los asalariados viven en pequeñas localidades o pueblos donde "todos" se conocen, lo que dificulta aún más la presencia de sindicatos (Dominzain, 2003; Barrios et al., 2007). Un asalariado que se enfrenta a los patrones y que lucha por sus derechos rápidamente pasa a integrar las "listas negras" y se ve alejado del mercado de empleo. En el caso de la ganadería principalmente, donde el peón reside en el establecimiento, implica perder su trabajo y adicionalmente su lugar para vivir.

Vinculado a ello, un segundo grupo tiene que ver con el marco jurídico e institucional. En Uruguay, la tendencia ha sido legislar en forma separada para el sector rural. Ya desde las primeras leyes laborales se excluye a los asalariados agropecuarios apelando a las especificidades del agro (Barbagelata, 1983). Consecuentemente, la legislación laboral para los asalariados rurales se caracterizó por su rezago, y su igualación con los derechos que gozan los trabajadores urbanos fue un proceso lento y altamente resistido (Zapirain, 2011). Desde las organizaciones empresariales se fundamentó esta diferenciación en la necesidad de no romper mediante la legislación con el equilibro y armonía imperante entre los habitantes del medio rural (Frega, Maronna y Trochón, 1985; Riella, 2004). Esto es acompañado por la ausencia o débil presencia del Estado como garante del cumplimiento efectivo de las disposiciones vigentes en materia laboral y de seguridad social (González Sierra, 1994). Esta escasa incidencia del Estado se ve reflejada en la frecuente persecución sindical realizada por parte de los empresarios (listas negras y despidos) (Malig, 2003).

El tercer grupo de obstáculos se vincula a la propia organización del trabajo en el agro. Las características extensivas de la producción ganadera dominante en el país conllevan a una baja concentración de asalariados por establecimiento. ${ }^{3}$ Sumado a ello, la dispersión geográfica provoca un fuerte aislamiento de los asalariados, que dificulta toda forma de interacción regular no sólo entre sí, sino también con la comunidad (Latorre, 1991; Rocha, 1991). Otra limitante se vincula a los cambios tecnológicos que se produjeron en algunos sectores del agro, y que condujeron a una paulatina sustitución de mano de obra por la mecanización de los procesos productivos. Los mismos a su vez generan la incapacidad de formar sindicatos o de mantener su funcionamiento, con un reducido número de asalariados por establecimiento.

En los rubros más intensivos de mano de obra, la estacionalidad del trabajo genera dificultades para el mantenimiento de la actividad sindical y las acciones colectivas en los periodos interzafra (Carámbula et al., 2012). Los asalariados se dispersan, los cuadros sindicales se desperdigan y no hay formas de generar un sustento económico para la organización sindical al no tener cotizantes durante el año (Malig, 2003). 
Los procesos de tercerización y subcontratación de mano vinculados a las estrategias de flexiblización de las empresas también inhiben la sindicalización, lo que acrecienta las dificultades para establecer vínculos laborales permanentes (Riella y Mascheroni, 2015).

Estas fuentes de dificultades han evolucionado de manera diferente a lo largo del tiempo, imponiendo frenos o estímulos para la organización colectiva de los asalariados agrarios. En este artículo, se aborda la trayectoria reciente del sindicalismo en el campo uruguayo. Específicamente, se reflexiona acerca de cómo el mismo ha reaccionado ante un escenario político en el cual se produce la expansión y reconocimiento de los derechos laborales, y se abren ámbitos específicos para su participación institucional en las negociaciones colectivas sobre salarios y condiciones de trabajo en el sector.

Para esto se describen las trayectorias históricas que han tenido las distintas experiencias organizativas de los trabajadores agrícolas en el país, las cuales ponen de manifiesto cuáles han sido los elementos que han obstaculizado la sindicalización y la acción colectiva de estos sujetos sociales, y cómo ello ha sido afectado por el nuevo contexto sociopolítico que se ha transitado en la última década.

\section{Orígenes DEL SINDiCALISMO RURAL EN URUguay}

El sindicalismo en Uruguay se remonta a fines del siglo XIX, bajo la influencia de los migrantes de orientación anarquista, y en menor medida socialista, que forman los primeros sindicatos urbanos en la capital del país. ${ }^{4}$ En el año 1905, los anarquistas logran crear la Federación Obrera Regional Uruguaya (FORU). En los siguientes años, el movimiento sindical avanza con altibajos en los sindicatos por oficio predominantes en ese momento. Este proceso fue madurando y forjando un sindicalismo relativamente considerable para la época, pero centrado básicamente en la ciudad capital que era la caja de resonancia de las nuevas ideas revolucionarias y proletarias a nivel mundial. La organización de sindicatos comienza a desarrollarse en el ámbito fabril, donde predominan los saladeros y frigoríficos de la época, y también en los servicios de tranvías y ferrocarriles, lugares que concentran un importante número de trabajadores (Porrini, 2004). En la segunda década del siglo XX, impulsadas por los intensos debates en torno a la situación internacional que abre la Revolución Rusa, se crean otras dos 'centrales' sindicales: el Comité Pro Unidad Obrera (CPUO), de orientación comunista, y la Unión Sindical Uruguaya (USU), de mayoría anarcosindicalista y una minoría comunista.

En la década del treinta, los efectos de la gran crisis económica mundial en la calidad de vida y el empleo de los trabajadores uruguayos, así como la represión antisindical del régimen dictatorial de esos años, ${ }^{5}$ generaron el debilitamiento del sindicalismo nacional. Será a partir de la segunda mitad de los años treinta, con el aumento de la clase obrera industrial y de los trabajadores de servicios, que el movimiento sindical toma un nuevo impulso, ahora bajo la influencia de las corrientes marxistas-socialistas y comunistas. En 1942 se produce un importante intento de unificación, con la creación de la Unión General de Trabajadores (UGT).

\section{LOS PRIMEROS ANTECEDENTES DE SINDICALISMO AGRARIO}

En el contexto reseñado emergen los primeros movimientos sindicales en el campo reivindicando mejoras salariales y de las condiciones de trabajo. En 1932 se registra la primera medida de lucha colectiva en un arrozal en el departamento de Treinta y Tres, poco tiempo después de implantado el cultivo de arroz en el agro uruguayo, donde los trabajadores realizan una huelga espontánea que logra mantenerse efectiva por cinco días a pesar de la intensa represión patronal y militar. Desde la patronal se responde con la aplicación constante de prácticas antisindicales como despidos, utilización de "listas negras" y desconocimiento de los derechos laborales.

En el ámbito rural, en 1943 ya se habían conformado el Sindicato Obrero Agrario de Salto, el Sindicato Agrario de San Javier (Río Negro), el Sindicato de Obreros de Oficios Varios de Nuevo Berlín (Río Negro) 
y el Sindicato Agrario del Semillero Nacional de La Estanzuela (Colonia). A partir de la década del 40 se desarrolla la sindicalización en los tambos vinculada a los sindicatos de oficios varios en algunas localidades del sur del país, siendo el primero el Sindicato de Peones de Tambo de Mendoza (Florida) ya funcionando en 1943. En 1944 se organizan los peones remolacheros de Paysandú. Un año después, en 1945, los esquiladores se organizan en alianza con el apoyo de la FOL (Federación de Obreros en Lanas), y plantean acciones de huelga en estancias que llevan a la sanción de leyes especiales sobre salarios mínimos. En 1946 se crea la Federación de la Industria de la Leche cuyos trabajadores asalariados realizan varias huelgas y logran así incidir en el proceso legislativo de la organización de la industria láctea (González Sierra, 1994).

\section{LA EXCLUSIÓN DE LOS CONSEJOS DE SALARIOS}

La fuerza y desarrollo del sindicalismo urbano se va a consolidar a mediados del siglo XX, con la creación de las diferentes centrales sindicales y el impulso brindado por la creación de los consejos de salarios del año 1943, en el marco de las políticas de integración social y una fuerte regulación de la economía por parte del Estado. Comienza así un proceso de acumulación de fuerzas del sindicalismo urbano, que desembocará en 1961 en la formación de la Central de Trabajadores de Uruguay (CTU), y posteriormente en la creación de una única central de trabajadores en el país (Convención Nacional de Trabajadores).

Pero los asalariados rurales quedan excluidos de la ley de creación de los consejos de salarios. ${ }^{6}$ Esto fue sin dudas uno de los mayores golpes que recibió el sindicalismo rural, y marcó el retroceso más notorio en el marco normativo, ya que consolidó las desigualdades entre los asalariados urbanos y los rurales.

Los pocos gérmenes sindicales que existían en el momento fueron debilitados por esta decisión. Se impuso el fuerte peso político de las clases dominantes del agro, que utilizaron todas sus fuerzas para bloquear este cambio que se consideraba que lesionaba los intereses de los ganaderos (Frega, Maronna y Trochón, 1985). En vez de incluirlos en una ley como al resto de los trabajadores, se creó un Estatuto específico del Trabajador rural (aprobado en 1946), en el que se limitan las capacidades de acción del sindicalismo en el campo.

A pesar de estos frenos al otorgamiento de derechos sindicales y las pésimas condiciones de trabajo, algunos núcleos sindicales resisten con el apoyo de determinadas organizaciones políticas y religiosas. En 1950 toma un nuevo impulso la organización sindical en las arroceras de Treinta y Tres y se funda el Sindicato Único de Arroceros (SUDA). En 1956, después de una difícil huelga, el SUDA logra celebrar un convenio colectivo, cuyo incumplimiento provoca una nueva en huelga que culmina en una fuerte represión. En 1957 se forma el Sindicato Único de Obreros Rurales (SUDOR) a partir de movimientos espontáneos que denuncian las malas condiciones en las plantaciones de remolacha en Paysandú. Entre los años 1956 y 1957 se realizan huelgas y marchas a Montevideo del Sindicato Único de Peones de Tambo (SUPT), SUDA y SUDOR, que en el caso de las huelgas de los peones de las plantaciones de arroz culmina en un paro general parcial de la Unión General de Trabajadores (UGT). Estas acciones sindicales fueron otra vez fuertemente reprimidas y sus dirigentes perseguidos. A pesar de estas derrotas, dos años más tarde (1959) se crea la Unión de Regadores y Destajistas de El Espinillar (URDE), que congregó a los trabajadores de la empresa estatal $\mathrm{ANCAP}^{7}$ en el norte del país (González Sierra, 1994).

Este esfuerzo de organización sindical en el campo recibió el apoyo de los sindicatos obreros urbanos ya fortalecidos, y paulatinamente comenzó a producirse el reconocimiento de la especificidad de la problemática de los asalariados rurales, que hasta el momento había permanecido invisibilizada detrás de una lógica que había priorizado políticamente la organización de los pequeños productores familiares y campesinos, como agentes subalternos aliados de la clase obrera en el agro. 


\section{IMPULSO DE LOS AÑOS 60}

Otro empuje importante que tuvo en estas décadas el sindicalismo rural fue la influencia de los procesos revolucionarios latinoamericanos, particularmente el cubano, cuya fuerza social se radicaba en las zonas rurales. En esta década y hasta el golpe de Estado de 1973 existieron aproximadamente 30 iniciativas de organización sindical en el país con diferente grado de éxito y consolidación (González Sierra, 1994).

En 1961 se funda la Unión de Trabajadores Azucareros de Artigas (UTAA) en las plantaciones de caña de azúcar en el departamento de Artigas, la experiencia más destacada de sindicalización agraria uruguaya, que contó con la promoción y apoyo del Movimiento de Liberación Nacional -Tupamaros (MLN). ${ }^{8}$ Estos trabajadores realizaron una serie de luchas sindicales que les permitieron alcanzar algunos éxitos parciales como el pago de salarios mínimos legales, el pago de dinero adeudado y la mejora de las condiciones de algunas viviendas. En 1962 por primera vez un sindicato rural utiliza la modalidad de huelga con ocupación de lugares de trabajo, ya extendida en esos años entre los trabajadores urbanos. La característica más saliente de sus acciones fue la realización de marchas a pie hacia Montevideo (630 kilómetros), que pasaban y acampaban por varias localidades del interior del país en las que daban a conocer las duras condiciones de trabajo en el medio rural. En estas marchas se puso de manifiesto la solidaridad del resto de la clase trabajadora organizada con los trabajadores agrarios del país.

Bajo la influencia de este movimiento se retoma la acción colectiva en las plantaciones de arroz, con la creación de la Unión de Trabajadores Arroceros de Artigas (UTAA) y la Unión de Trabajadores Arroceros del Este (UTAE) en Treinta y Tres. En 1964 se constituye en Rocha el Sindicato Único de Peones Arroceros (SUPA), filial de la Central de Trabajadores del Uruguay y más adelante de la CNT. En 1963 se reorganiza el Sindicato Único de Peones de Tambo. Se crean también núcleos sindicales de peones de las quintas próximas a Montevideo, en viñedos de bodegas de Río Negro, en plantaciones de tabaco en Tacuarembó, y con esquiladores en varios departamentos (González Sierra, 1994).

Todos los sindicatos agrarios mantuvieron relaciones con las centrales sindicales nacionales de cada época. ${ }^{9}$ De esta forma, sus acciones colectivas fueron acompañadas y respaldadas por los sindicatos de trabajadores de la industria, comercio y funcionarios públicos. También contaron con la promoción e incluso conducción a cargo de asalariados pertenecientes a los partidos de izquierda, principalmente los partidos Socialista, Comunista y el Movimiento de Liberación Nacional.

Este respaldo de la central obrera nacional se refleja en que las demandas de los sindicatos agrarios pasan a integrarse al conjunto de las demandas del sindicalismo uruguayo. Se incorpora específicamente como un tema de agenda permanente para el movimiento sindical la convocatoria a los consejos de salarios en el medio rural, la ley de ocho horas y la aplicación de las leyes laborales vigentes en el medio urbano para el asalariado rural.

En 1971 se crea la primer Federación Nacional de Trabajadores Rurales del Uruguay (FNTR) ${ }^{10}$ con el objetivo de "seguir la lucha por el salario, por elevar el nivel de vida de los asalariados y por el respeto de la legislación social y laboral existente en el país” (tomado de González Sierra, 1994, p. 70). Si bien la fundación fue producto de la intención de dar un agrupamiento estable a los sindicatos rurales, el contexto político y social adverso, y la persecución de la cual fueron objeto sus dirigentes no le permitieron alcanzar su pleno funcionamiento.

A pesar de que en este periodo no se lograron triunfos que pudieran representar un avance significativo para la sindicalización en el campo, sí se produjo una fuerte concentración de experiencias y energías, que pudieron haber terminado en la consolidación de sindicatos rurales. Pero el proceso de represión y la dictadura cívico militar a partir del año 1973 truncaron este desarrollo sindical, prohibiendo y llevando a la clandestinidad las actividades sindicales.

Durante la dictadura, uno de los sectores que más sufrió la negación de los derechos laborales y un fuerte sistema de control que impidió cualquier impulso de sindicalización fue sin dudas el sindicalismo rural. Las 
organizaciones patronales fueron una de las bases sociales del golpe de Estado y utilizaron toda su influencia y poder para bloquear cualquier intento de acción colectiva de los trabajadores, imponiendo además un nuevo Estatuto del Trabajador Rural (1978) que reafirma la condición de subordinación de estos asalariados, inhibiendo nuevamente las posibilidades de avance del sindicalismo agrario.

\section{LA REDEMOCRATIZACIÓN Y EL SINDICALISMO RURAL}

Una vez retomada la democracia en el país en 1985 comienza una etapa de resurgimiento y reorganización de los sindicatos rurales a un ritmo sin precedente histórico, pero con muchas dificultades y limitaciones: en 17 meses se crearon 14 sindicatos de asalariados rurales, que agrupaban a 5.000 trabajadores (González Sierra, 1994). Se reorganizan el Sindicato Único de Peones de Tambo (SUPT) y la Unión de Trabajadores Azucareros de Artigas (UTAA). En 1984, aún en dictadura, se crea el Sindicato de los tabacaleros de Tacuarembó y Rivera (ALTRATA). En 1985 se fundan el Sindicato Único de Trabajadores Rurales de Artigas (SUTRA), el Sindicato de Obreros Rurales y Destajistas de San José (SORYDESA), el Sindicato Único de Asalariados Rurales de Paysandú (SUARP), el Sindicato Único de Trabajadores Arroceros (SUTA), el Sindicato de Frutas y Verduras de Salto (SOFYV), el Sindicato de Obreros de Tranqueras (SORT), la Asociación Laboral de Trabajadores de Tabacaleros (ALTRATA), el Sindicato de Único de Obreros Rurales de Cerro Largo (SUDOR), el Sindicato Único de Asalariados Rurales y Afines (SUARA), el Sindicato de Obreros Rurales de Salus (SORS). En 1988 se crea la Asociación de Empleados de los Viñedos de Villa del Carmen (AEVIC). En 1989 se funda el Sindicato Único de Calagua (SUCAL). Los trabajadores forestales se congregan en el Sindicato Único de Obreros de la Industria de la Madera y Afines (SOIMA).

Las principales reivindicaciones de los sindicatos a la salida de la dictadura siguieron girando en torno al incremento de los niveles reales de salarios, garantías para el pleno ejercicio de los derechos gremiales, el cumplimiento de las leyes y convenios vigentes, convocatoria a los consejos de salarios rurales, limitación de la jornada laboral y descanso semanal, mejora de las condiciones de trabajo y de los beneficios sociales, y discusión de un nuevo estatuto del trabajador rural (Latorre, 1993).

A mediados de los ochenta se realizan nuevos intentos de crear una federación nacional de trabajadores rurales que nuclee a todos los sindicatos del sector. En 1985, 11 de los sindicatos existentes (salvo UTAA) fundaron la Federación Nacional de Asalariados Rurales (FENARU) que tuvo como principal bandera la creación de un Nuevo Estatuto del Trabajador Rural.

Pero las disputas políticas en la interna del sindicalismo agrario provocaron una tensión fuerte dentro del sindicalismo nacional y crearon un sismo en el tercer Congreso del PIT-CNT ${ }^{11}$ del año 1986. Este episodio, si bien fue ampliamente superado por el movimiento sindical unos meses después, representó para el sindicalismo rural cierto retroceso en el respaldo que recibía de la central nacional, dado que no pudieron resolver sus propios conflictos y los trasladaron al resto de los trabajadores organizados. En los años siguientes, la central obrera fue más cautelosa en su apoyo y menos entusiasta con el sindicalismo rural como en la predictadura. Recién en 1990 se aprueba la creación del Departamento de Asalariados Rurales, integrado por sindicatos rurales y un miembro de la directiva de la central obrera nacional.

El gobierno recién electo había acordado con las fuerzas sociales una agenda de acciones entre las que se incluía la convocatoria a los consejos de salarios en el sector rural. Esto hubiese significado un fuerte respaldo a la acción sindical del medio rural, pero ante el intento de convocatoria, las gremiales ganaderas protagonizaron un fuerte conflicto abierto con el Ministro de Trabajo y Seguridad Social de la época, que impidió llevar la negociación tripartita al medio rural y debilitó aún más las energías para el desarrollo de la acción colectiva en el agro.

Pero más allá de esta exclusión, en estos años se produjeron varios intentos de sindicalización y movilización, lo que logró consolidar una estructura sindical mínima, que mantuvo vigentes los reclamos de los trabajadores rurales dentro de la central nacional de trabajadores. Según un relevamiento realizado 
por Latorre (1993b) en el año 1993 existieron 8 sindicatos rurales que sobrevivieron a este proceso, representativos de los sectores de caña de azúcar, forestación, citrus, fruticultura y viticultura, localizados principalmente en el norte y sur del país. ${ }^{12}$

El impulso del sindicalismo rural postdictadura se fue así frenando paulatinamente en la medida en que las principales dificultades y trabas para su desarrollo persistían. De hecho, muchos de los sindicatos creados tuvieron una acción efímera, y no se logró expandir la sindicalización a nuevos sectores. Entre 1985-1993 se desintegraron unos 7 sindicatos de los sectores de arroz, tambo, tabaco, remolacha, citrus y vid. Las causas de la desaparición de estas organizaciones estuvieron asociadas principalmente a las dificultades de funcionamiento en ámbitos de baja concentración de trabajadores, la desaparición asociada a la pérdida de importancia del rubro, los despidos, y la falta de un grupo de dirigentes que llevara adelante la organización sindical (Latorre, 1993b). También en estas circunstancias dejó de funcionar la FENARU, lo que hizo más frágil su representación en la central sindical nacional en los últimos años de este periodo.

El avance de la desregulación laboral de corte neoliberal en la década de los noventa disminuyó la fuerza del sindicalismo en general y en particular del sindicalismo agrario. Todo esto llevó a que inicios de este siglo los niveles de sindicalización fueran muy bajos, con sindicatos concentrados en las cadenas agroindustriales y con nula penetración entre los trabajadores de la ganadería y agricultura.

Esta situación mostraría una leve inflexión con la crisis agropecuaria que atravesará el país en el año 2001. En ese contexto, por presión de los sindicatos se incluye por primera vez la aplicación del seguro de paro a los asalariados rurales, aunque todavía en situación de desventaja frente a sus pares urbanos. Pese a ello, la extensión de este beneficio será un indicador de la visibilidad que comenzará a tomar el tema de los derechos laborales para este grupo social en los próximos años con el cambio de gobierno.

\section{EL SINDICALISMO RURAL EN EL NUEVO SIGLO}

A partir del año 2005, con el ascenso del Frente Amplio ${ }^{13}$ al gobierno, el escenario para el sindicalismo rural cambiará sustantivamente, ya que se iniciaría un proceso de reconocimiento de sus derechos laborales y sus organizaciones sindicales, lo que otorgaría un respaldo inusitado a la acción colectiva de los asalariados en el campo.

Este impulso a la sindicalización no fue sólo para los asalariados rurales, sino que desarrolló una acción de respaldo a todo el movimiento sindical en el país, que repercutió en su fuerte crecimiento. ${ }^{14}$ No obstante, que se haya puesto un énfasis especial en el sindicalismo rural fue un reconocimiento específico al retraso que este sector tenía en el país. De hecho, una de las primeras medidas del gobierno, anunciada durante el discurso de asunción del presidente, fue la convocatoria a los consejos de salarios, esta vez incluyendo a los trabajadores rurales. Esto fue posible, porque a raíz de la grave crisis económica que vivió el país en el 2002, los sectores dominantes del agro sufrieron un retroceso importante en su poder y legitimidad, que no les permitió vetar el nuevo marco normativo de las relaciones laborales para el sector impulsado por el novel gobierno.

Durante los gobiernos del Frente Amplio, los asalariados rurales fueron considerados como sujeto de desarrollo rural. Un desarrollo rural concebido desde una nueva perspectiva, con un fuerte eje en la reforma laboral, y no centrado solamente en lo vinculado al apoyo a la producción familiar y pequeños productores (Riella y Mascheroni, 2015). Y que, por tanto, incorpora la problemática del sujeto principal del medio rural, el asalariado agrario, que a diferencia de otros países de la región representa la mayoría absoluta de la PEA agropecuaria. Por ende, en un mundo rural poblado predominantemente por asalariados rurales, el mercado de empleo se reconoce como institución fundamental para la redistribución de los excedentes en el sector agropecuario.

En consonancia con ello, en pocos años se aprobó un conjunto de medidas que afectará las relaciones laborales del país, algunas específicas para el sector, y otras de carácter general, pero con un alto impacto en 
el agro, dado el mencionado retraso histórico que prestaba el sector en esta materia, como se muestra en el cuadro a continuación.

En estos años la legislación referida al trabajo rural pretendió homologar paulatinamente esta actividad con el trabajo en otros sectores. Con este objetivo, los asalariados agrarios son alcanzados por las principales leyes que se promulgan en el periodo, referidas a las garantías para la actividad sindical y la negociación colectiva. ${ }^{15}$ También se promulgan leyes específicas que tienen que ver con la limitación de la jornada laboral, la modificación del Estatuto del Trabajador rural, la fijación del día del trabajador rural (feriado pago no laborable) y ciertas disposiciones sobre salud laboral.

TABLA 1

Medidas de regulación laboral (2005-2015)

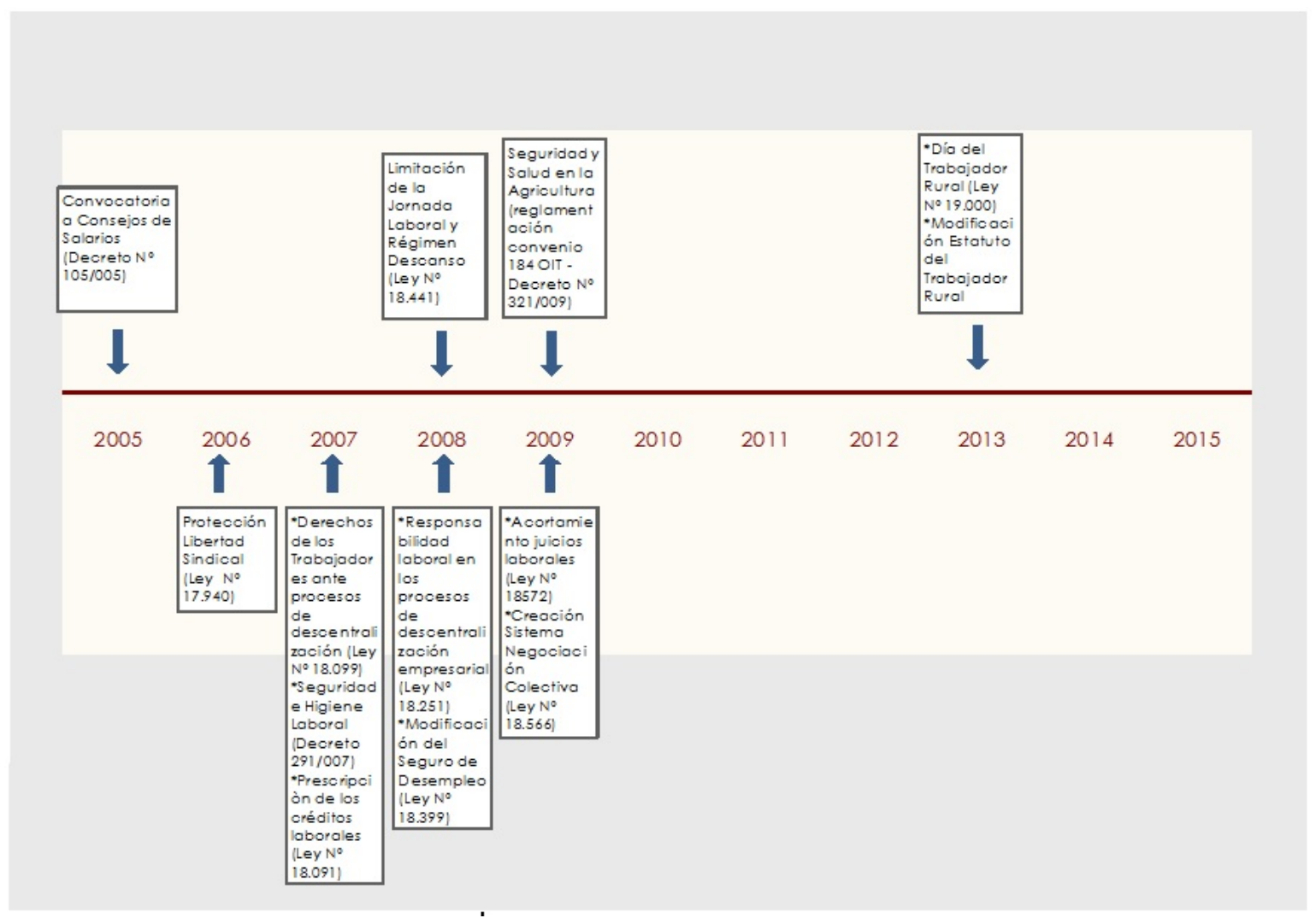

Elaboración propia

A su vez, se fortalecen los espacios de control del Ministerio de Trabajo y Seguridad Social, aumentando las inspecciones a las empresas rurales y agilitando los procesos de denuncias de los trabajadores sobre violación a sus derechos laborales y sindicales por parte de los patrones. Este Ministerio realiza también una campaña pública de divulgación de los derechos de los asalariados bajo el lema "Los derechos de los trabajadores rurales asalariados no son paye, ${ }^{16}$ son ley".

En el gobierno se incorpora la problemática del asalariado rural y la organización sindical es promovida como mecanismo para el cumplimiento y fortalecimiento de los derechos laborales de los asalariados. El Ministerio de Ganadería, Agricultura y Pesca a través de la Dirección de Desarrollo Rural tomó a los asalariados rurales y sus organizaciones como un destinatario principal de sus políticas públicas. También en el Instituto Nacional de Colonización se realizan las primeras experiencias de colonización con asalariados.

El desarrollo de esta promoción de los derechos de los asalariados rurales se produce concomitantemente con cambios en el interior de la organización de los procesos de trabajo que tienden a reducir el empleo y la flexibilización de las formas de contratación con base en la intermediación de mano de obra. Estos cambios 
modifican las características de la mano de obra asalariada rural, la cual aumenta aún más su residencia urbana, la participación de las mujeres y su movilidad territorial. También se incorporan en las empresas con gran concentración de trabajadores procesos de certificación para garantizar los estándares de calidad exigidos por los mercados de destino de sus exportaciones, que en algunos casos permitieron la tolerancia de la acción sindical de estas empresas (Moraes y Cutillas, 2014). Pero, en general, las transformaciones acaecidas no parecen haber alterado significativamente las trabas impuestas por la organización del trabajo agrario a la sindicalización en el sector (Riella y Mascheroni, 2015).

\section{EFEctos DE LA NUEVA LEGISLACIÓN EN EL SINDICALISMO RURAL}

En estos años, las políticas reseñadas estimularon el sindicalización rural. Entre ellas, la convocatoria a los consejos de salarios fue el mayor estímulo para el desarrollo del sindicalismo en el campo, como lo había sido cinco décadas atrás para el sindicalismo urbano.

Este nuevo impulso sindical queda expresado en el incremento del número de organizaciones de los asalariados que se produce desde el 2005, que alcanzó sectores en los cuales antes no existía y que revitalizó organizaciones sindicales que venían muy debilitadas o habían dejado de funcionar por años (ver anexo). El crecimiento cuantitativo de los sindicatos rurales fue acompañado por un incremento en la cantidad de afiliados, aunque su número es muy difícil de estimar con exactitud. ${ }^{17}$ La participación en los espacios de negociación colectiva permitió dar continuidad a la organización sindical y brindó la posibilidad de ir formando delegados sindicales y liderazgos -al proporcionarles un espacio para aprender y ejercitar la defensa de sus intereses colectivos-, y les impulsó a promover mecanismos para articular a nivel nacional.

La conformación de un sindicato que representaba los intereses de los asalariados de la ganadería marcó un hito importante en el sindicalismo rural. Si bien su peso es muy débil, simbólicamente es muy importante, ya que la ganadería emplea a casi la mitad de los trabajadores del sector, y debido a las condiciones propias de la actividad - marcadas por el aislamiento de los trabajadores, la relación paternalista patrón-trabajador, la estrecha interrelación de las relaciones de convivencia con la relaciones laborales y el poder de los estancieros-, nunca habían contado con una organización que reclamara por los derechos de los peones de estancia.

Para inicios del 2005 se recrea una central nacional de asalariados agrarios, la Unión Nacional de Asalariados, Trabajadores Rurales y Afines (UNATRA), en la ciudad de Bella Unión, conformada por 6 sindicatos. La UNATRA está afiliada al PIT-CNT y reúne una diversidad de sindicatos y asalariados rurales nucleados en torno a un rubro, una región o una empresa, sindicatos con historias y trayectorias muy disímiles.

En el año 2007 cuenta ya con 16 organizaciones, la mayoría de reciente formación, a impulso de la convocatoria a los consejos de salarios (Mascheroni, 2011). Una década después, estos sindicatos continúan funcionando, mostrando una estabilidad en el tiempo no frecuente en épocas anteriores.

También en esta década, la fuerza de los movimientos feministas en el país fue un estímulo para la participación de las mujeres en los sindicatos rurales, y dio lugar a algunos liderazgos femeninos que han sido muy relevantes para dar continuidad a varios sindicatos. La discusión de género estuvo presente en los sindicatos rurales y se trataron de incorporar en la agenda de los consejos de salarios ciertas consideraciones al respecto, como por ejemplo la no discriminación laboral femenina y una jornada semanal menor para las mujeres (con pago equivalente).

En este nuevo escenario los sindicatos agrarios fueron adaptando sus acciones reivindicativas a nivel local y nacional. Las mejoras salariales y de las condiciones de vida de los asalariados, así como los avances legales de estos años, inhibieron en los hechos la emergencia de conflictos de gran envergadura, no presentándose ninguna situación de este tipo en el periodo. Los empresarios, por su parte, optaron por evadir los conflictos abiertos, y advirtieron tempranamente que frente al decisivo apoyo formal del gobierno al sindicalismo rural en las instancias institucionales era necesario adaptar su compartimiento a las nuevas normativas. Esto 
sucedió especialmente en las empresas rurales de mayor porte, en las que todos los trabajadores tenían empleos formales, y en las condiciones de trabajo establecidas por la ley. También presionaron por la inclusión de procedimientos para canalizar conflictos y cláusulas de paz en los diferentes grupos de los consejos de salarios.

Durante todo este periodo la disputa simbólica más importante de las organizaciones -en las esferas institucionales establecidas para tal fin (consejos de salarios) - fue por el reconocimiento de las organizaciones sindicales y por los derechos laborales. Las patronales en esta situación no tuvieron una estrategia de conflicto abierto, sino que optaron por el retiro sistemático de los ámbitos de negociación colectiva evitando así firmar la mayoría de los acuerdos alcanzados para la ampliación de los derechos laborales de los trabajadores, como forma de protesta frente a lo que ellos denunciaban como falta de imparcialidad del gobierno en estos espacios.

En este clima, al no tener que enfrentar con tanta frecuencia conflictos extremos y una represión abierta para sus liderazgos, el espacio para la acción sindical se fue desarrollando al amparo institucional de la negociación colectiva. Esto ha derivado en al menos cuatro tipos de acciones o estrategias gremiales que han permitido fortalecer la acción sindical y reducir en algo la asimetría en las relaciones de poder con los empresarios.

La primera y más básica es la vía de la judicialización individual de los casos que violentan las leyes y no respetan las normas establecidas. Ello sin dudas ha sido una gran herramienta para hacer respetar los derechos de los trabajadores, pero como en general se produce una vez que se rompe la relación laboral, no suele tener mayor incidencia en la acción sindical directamente. No obstante, muchos trabajadores, después de pasar por esta experiencia de juicios a los patrones, toman conciencia de sus derechos y de su posibilidad de reclamarlos, y, en algunos casos, emprenden un camino de acción sindical y pasan a integrar o militar en su sindicato de rama, especialmente en los casos de los que realizan tareas zafrales.

Un segundo camino, que ha sido transitado por varios sindicatos con problemas de organización, fue el de propiciar ellos mismos los juicios por incumplimiento de la legislación laboral en aquellos lugares donde tenían afiliados. Esto constituía una estrategia de acción sindical para dar visibilidad y poder al sindicato frente a los trabajadores. A su vez, judicializar el conflicto resultaba una forma de enfrentar el poder de la patronal sin tomar medidas gremiales propiamente dichas.

Un tercer mecanismo, llevado adelante por los sindicatos más fuertes del sector, era negociar las infracciones o incumplimientos de manera colectiva con las patronales e intentar, mediante presión y medidas de fuerza, corregir la situación sin judicializar los casos ni individualizarlos. Esta es la situación de la forestación, la caña de azúcar, la citricultura y el arroz, y ha permitido a dichas organizaciones afianzar el sindicalismo en su ámbito de acción en comparación con los otros sindicatos rurales. En estos rubros se logran firmar en los consejos de salarios convenios más avanzados que en los otros rubros.

Una cuarta estrategia, utilizada en menor medida, fue colocar en la opinión pública las situaciones de violación de los derechos sindicales o laborales, mostrando principalmente los casos de abuso de poder, e inclusive de violencia física hacia los trabajadores. Por ejemplo, durante la discusión de la limitación de la jornada laboral realizaron una marcha desde el interior del país hacia Montevideo y colocaron carteles en espacios públicos con el lema "Los trabajadores del campo también tenemos derecho al descanso".

\section{REFLEXIONES FINALES}

El recorrido del sindicalismo rural en Uruguay tiene ya casi 90 años. En su larga historia ha enfrentado muchas dificultades y obstáculos para su consolidación, como se expuso en las páginas anteriores. Pero en todas esas décadas de luchas, resistencia y duras derrotas se fue logrando una acumulación de fuerzas que permitió alcanzar en este siglo un avance sustantivo de sus objetivos históricos. La plataforma de reivindicaciones que se fue forjando desde las primeras luchas sindicales de principios del siglo pasado recién en esta década logra imponerse como derechos efectivos para los asalariados rurales. Hoy los 
sindicatos agrarios están formalmente reconocidos y sus cuadros pelean por fortalecer y ampliar sus organizaciones. En la medida que se lo permite su escasa fuerza de movilización, enfrentan a las patronales en sus prácticas más represivas y negocian en espacios institucionales mejoras salariales y de sus condiciones de trabajo.

Pero estas organizaciones continúan siendo muy débiles, dado que los obstáculos para el desarrollo del sindicalismo en el campo -mencionados al inicio de este artículo- en su mayoría siguen vigentes. Con excepción de las limitantes vinculadas al marco legal e institucional, que varía significativamente desde el año 2005, las restantes trabas no se han podido derribar. En este sentido, las relaciones de fuerza siguen siendo extremadamente adversas para los trabajadores agrarios y sus sindicatos. Adicionalmente, el poder simbólico que ejercen las clases dominantes inhibe la participación de los asalariados en sus sindicatos y en las acciones de reclamo de sus derechos, aunque en los últimos años, como se mostró anteriormente, por la vía de la judicialización de los conflictos se abre un camino de visibilidad social de los mismos, que puede dar frutos para consolidar y ampliar el sindicalismo actual.

Por su parte, los obstáculos vinculados a los procesos de trabajo en el agro no se han modificado sustancialmente. La dispersión y aislamiento de los trabajadores siguen estando presentes más que en otras ramas de actividad. Los avances tecnológicos, si bien han permitido la residencia urbana de muchos asalariados, también han reducido la cantidad de mano de obra necesaria en aquellos rubros en los que los sindicatos rurales se originaron y tenían mayor presencia. A su vez, la profundización de los procesos de subcontratación y tercerizaciones de la mano de obra han sido un factor inhibidor de las acciones sindicadas en el agro. Si bien la fuerte formalización del trabajo que se produjo en esta década y el control sobre los intermediarios de mano de obra por parte del Estado permitieron mitigar algunos de los efectos negativos de estas prácticas empresariales, las mismas han tenido un efecto nocivo sobre el sindicalismo rural como en el resto de toda América Latina.

Si retomamos los tres factores que inhiben el desarrollo del sindicalismo rural, es posible pensar que el avance de la normativa y legislación, sin un cambio significativo en la organización del trabajo y el mantenimiento del enorme capital económico, social y simbólico que detentan los sectores dominantes, no permite remover fácilmente las trabas para la organización de los trabajadores agrarios.

En este sentido, es importante remarcar que el sindicalismo rural en Uruguay se desarrolla en un espacio social donde se produce el enfrentamiento de uno de los grupos más poderosos del país contra uno de los más débiles. Por tanto, la experiencia muestra que es imprescindible la mediación estatal para corregir estas enormes asimetrías y permitir un desarrollo mínimo de la acción sindical en el campo. Sin una intervención decidida en esta dirección, como ha quedado comprobado para el caso uruguayo, es muy difícil la consolidación de organizaciones que representen los intereses de los asalariados del campo y la conquista de derechos fundamentales consagrados para el resto de los trabajadores.

Pero la existencia de garantías sindicales no limita por sí sola la fuerte oposición de las patronales rurales a la organización de los trabajadores. La libre organización colectiva y las libertades sindicales siguen siendo resistidas por las patronales, las cuales buscan "frenar" o minimizar las normativas al respecto ejerciendo presión sobre el gobierno, y aumentando las medidas de control y represión encubierta a los trabajadores sindicalizados a nivel de las empresas. Este escenario abre nuevos desafíos para la consolidación y crecimiento de los sindicatos existentes en los próximos años, puesto que desde el gobierno se han utilizado las herramientas institucionales de las que se disponía para brindar su apoyo a las organizaciones de trabajadores del agro.

Para finalizar estas reflexiones es necesario rescatar la particularidad que tiene este proceso histórico de formación de sindicatos en relación a América Latina. En primer lugar, en pocos países de este continente se ha logrado una centralidad tan importante de la defensa de los derechos de los asalariados rurales como sujeto específico y separado de las demandas campesinas y de la agricultura familiar. En este sentido, la amplia mayoría de las luchas y reivindicaciones sindicales han puesto énfasis en la condición de proletariado agrícola y no de productor rural. De hecho, el reclamo de tierras y acceso a la producción no ha sido el eje principal en 
estas décadas de lucha. Si bien estas demandas estuvieron algo más presentes a inicios de los 60, jugaron un rol secundario en el proceso de estos últimos años, tanto desde un punto vista simbólico como de legitimación frente al resto de la sociedad. Un segundo punto que también parece contribuir a esta diferenciación con el resto de la región es el real peso que ha tenido históricamente el asalariado rural en el conjunto de la población rural. Uruguay se diferencia de la mayoría de las estructuras agrarias del continente donde la tradición campesina, indígena y comunitaria constituye parte indisoluble de la ruralidad y la cuestión agraria. En nuestro país la ruralidad está determinada por el fuerte peso de los asalariados en la PEA del agro, que alcanzan a casi el $70 \%$, por lo que hoy parece haber una correspondencia entre esta realidad y las medidas tomadas en estos últimos años en el plano formal y normativo.

Para terminar, se debe considerar también que este sindicalismo rural tardío se desarrolla en un siglo en el cual operan transformaciones sociales más amplias, en el que las organizaciones sindicales se ven continuamente interpeladas por las crecientes tendencias a la individualización de la sociedad y por la pérdida de legitimidad de este tipo de acciones colectivas. Estas tendencias no escapan al medio rural y a los trabajadores agrarios, por lo cual este escenario también debe ser valorado para evaluar sus logos de este período.

\section{REFERENCIAS BIBLIOGRÁFICAS}

Aparicio, S., Ortiz, S. y Tadeo, N. (2008). Have Private Certifications Benefited Laborers? Lemon and Sweet Citrus Production in Argentina. (Las certificaciones privadas benefician a los trabajadores. La producción de limón y cítricos dulces en Argentina). Globalizations. Vol. 5 (2), 167-181

Barbagelata, H. (1983). Derecho del Trabajo. Tomo III. Montevideo: FCU.

Barrios, M.; Ciarniello, M.; y Moreira, B (2007). Una experiencia de Diálogo Social en el medio rural: la convocatoria al Consejo Tripartito Rural. Boletin CINTERFOR 157, 145-166

Buxedas, M. (1988) Asalariados y patrones: la realidad de nuestro campo. Documento de Trabajo No 52. Montevideo: CIEDUR.

Carámbula, M.; Cardeillac, J.; Moreira, B.; Gallo, A.; Juncal, A.; Piñeiro. D. (2012). Los límites de la ciudadanía: el caso de los trabajadores asalariados rurales. En: Riella, A. (coord.) El Uruguay desde la Sociología X (pp. 351-370). Montevideo: DS. FCS. UdelaR.

Crespo, M. (2015) Dinámica de las negociaciones y conflictos de asalariados citrícolas durante la última década en Tucumán, Argentina. Estudios del Trabajo N50, 153-180

Dominzain, S. (2003). Las trabajadoras del cítrico en Uruguay. Condiciones de trabajo y derechos laborales. Estudios del Hombre, Vol. 16, $243-267$

Frega, A.; Maronna, M. y Trochón, Y. (1985). Los Consejos de Salarios como experiencia de concertación. Cuadernos de CLAEH, Vol. 33, 14 - 36

González Sierra, Y. (1994). Los olvidados de la tierra. Vida, organizaciones y luchas de los sindicatos rurales. Montevideo: Comunidad Nordan.

Juncal, A.; Carámbula, M. y Piñeiro, D. (2015). Mapas y proyectos de ciudadanías de las organizaciones sindicales de los asalariados agropecuarios del Uruguay. En: Pucci, F. (org) Sindicalización y negociación en los sectores rurales $y$ domésticos (pp 73-89). Montevideo: CSIC.

Latorre, R. (1986). Asalariados rurales. Ficha bibliográfica No 13. Facultad de Agronomía. Cátedra de Sociología. Montevideo: FCU.

Latorre, R. (1991). Los asalariados rurales en el Uruguay. Montevideo: FAgro-UdelaR.

Latorre, R. (1993a). Los asalariados Rurales. Revista Estudios, Vol. 110, $42-47$

Latorre, R. (1993b). Los trabajadores rurales Uruguay. Montevideo: FAgro-UdelaR.

Malig, A. (2003). Transformaciones agrarias y sindicatos rurales: El caso del Sindicato Único de Obreros Rurales y Agroindustriales (Monografía de grado inédita). Montevideo: DS. FCS. UdelaR. 
Mascheroni, P. (2011). Democracia y ciudadanía en el campo. Los primeros Consejos de Salarios Rurales en Uruguay. Montevideo: DS. FCS. UdelaR.

Moraes, N. y Cutillas, I. (2014). Nuevos dispositivos de regulación transnacional: un análisis sobre los estándares de calidad y responsabilidad social y su impacto en los enclaves globales agrícolas. En: Pedreño, A. (coord) De cadenas, migrantes y jornaleros. Los territorios rurales en las cadenas globales agroalimentarias (pp 194-218). España: Talasa.

Moreira, B. (2010) El juego de la mirada. Inferencias sobre el trabajo y los procesos de contratación en la ganadería, a partir de un estudio de caso en el noreste de Durazno. En: Aparicio, S.; Neiman, G. y Piñeiro, D. (coordinadores).Trabajo y trabajadores en el agro rioplatense. Nuevos temas y perspectivas (pp 125-144). Montevideo: Letraeñe.

Neiman, G. (2016). Mercados de trabajo y sindicalismo en producciones agrícolas reestructuradas de la Argentina. Trabajo y Sociedad, Vol. 27, 63-77.

Piñeiro, D. (2011) Precariedad objetiva y subjetiva en el trabajo rural: nuevas evidencias. Revista de Ciencias Sociales, Vol. 24 (28), 11-33

Porrini, R. (2004) (Comp.). Historia y memoria del mundo del trabajo. Montevideo: FHCE-UdelaR.

Rau, V. (2009). La acción colectiva de los asalariados agrícolas. Una revisión de estudios sobre sus características y condicionantes. Revista Interdisciplinaria de Estudios Agrarios, Vol. 31, 107-127.

Riella, A. (2004). Poder, luchas simbólicas y democracia: las gremiales ganaderas en el Uruguay contemporáneo (1985-2000). En: Mazzei, E. (coord.). El Uruguay desde la Sociologia II (pp 63-74). Montevideo, DS. FCS. UdelaR.

Riella, A. (2006). Los frenos a la construcción de ciudadanía en el campo: el caso de los asalariados rurales en Uruguay. En: De Grammont, Hubert (Comp). La construcción de la democracia en el campo latinoamericano (pp 159-185). Buenos Aires: CLACSO.

Riella, A. y Mascheroni, P. (2015). Transformaciones agrarias y cambios recientes en los mercados de empleo rural en Uruguay. En: Riella, A. y Mascheroni, P. (comps.), Asalariados rurales en América Latina (pp 237-262). Montevideo: CLACSO-UdelaR

Riella, A. y Mascheroni, P. (2017). Las politicas públicas y las organizaciones agrarias en el Uruguay progresista. Montevideo: CSIC.

Rocha, A. (1991). La sindicalización rural: los estímulos y las limitaciones para su desarrollo. Serie Seminarios y Talleres N. 43. Montevideo: CIEDUR.

Rocha, A. (2008). Construyendo ciudadanía junto a los trabajadores rurales. Montevideo: JUNAE.

Villulla, J. (2010) Política y sindicalismo en el gremio de los obreros rurales (1974-2001). Ponencia presentada en las VII Jornadas de Investigación y Debate La Argentina rural del siglo XX. Conflictos rurales en la Argentina del Bicentenario. Significados, alcances y proyecciones. Universidad Nacional de Quilmes (Buenos Aires, Argentina)

Zapirain, H. (2011) Régimen jurídico del trabajo rural. Revista de la Facultad de Derecho, Vol. 31, 317-337 


\section{Anexo}

TABLA 2

Sindicatos agrarios según rubro y periodo histórico

\begin{tabular}{|c|c|c|c|}
\hline Rubro principal & $\begin{array}{l}\text { Desde los orígenes al } \\
\text { golpe de Estado } \\
\text { (1930-1973) }\end{array}$ & $\begin{array}{l}\text { Redemocratización } \\
\quad(1985-2004)\end{array}$ & $\begin{array}{r}\text { Progresismo } \\
(2005-2015)\end{array}$ \\
\hline Forestación & & $\begin{array}{l}\text { Sindicato de Obreros } \\
\text { Industriales de la } \\
\text { Madera y Afines } \\
\text { (SOIMA) } \\
\text { Sindicato Único de } \\
\text { Obreros Forestales } \\
\text { (SUNOF) } \\
\text { Sindicato de Obreros } \\
\text { de Tranqueras (SORT) }\end{array}$ & $\begin{array}{l}\text { Sindicato de Obreros } \\
\text { Industriales de la } \\
\text { Madera y Afines } \\
\text { (SOIMA) } \\
\text { Sindicato Único de } \\
\text { Obreros Forestales } \\
\text { (SUNOF) }\end{array}$ \\
\hline Caña de azúcar & $\begin{array}{c}\text { Unión de Trabajadores } \\
\text { Azucareros de Artigas } \\
\text { (UTAA) } \\
\text { Unión de regadores y } \\
\text { destajistas de El } \\
\text { Espinillar (URDE) }\end{array}$ & $\begin{array}{c}\text { Unión de Trabajadores } \\
\text { Azucareros de Artigas } \\
\text { (UTAA) } \\
\text { Sindicato Único de } \\
\text { Trabajadores Rurales } \\
\text { de Artigas (SUTRA) }\end{array}$ & $\begin{array}{c}\text { Unión de Trabajadores } \\
\text { Azucareros de Artigas } \\
\text { (UTAA) } \\
\text { Unión de Trabajadores } \\
\text { Agrícolas de Belén } \\
\text { (UTABE) }\end{array}$ \\
\hline Remolacha azucarera & $\begin{array}{l}\text { Sindicato único de } \\
\text { Obreros Rurales } \\
\text { (SUDOR) }\end{array}$ & SUARP & \\
\hline Arroz & $\begin{array}{c}\text { Sindicato Único de } \\
\text { Arroceros (SUDA) } \\
\text { Sindicato Único de } \\
\text { Peones Arroceros } \\
\text { (SUPA) }\end{array}$ & $\begin{array}{l}\text { Sindicato Único de } \\
\text { Trabajadores Arroceros } \\
\text { (SUTA) }\end{array}$ & $\begin{array}{l}\text { Sindicato Único de } \\
\text { Trabadores del Arroz y } \\
\text { Afines (SUTAA) }\end{array}$ \\
\hline $\begin{array}{l}\text { Horticultura, } \\
\text { citricultura }\end{array}$ & & $\begin{array}{l}\text { Sindicato de Obreros } \\
\text { Rurales y Destajistas de } \\
\text { San José } \\
\text { (SOR YDESA) } \\
\text { Sindicato Único de } \\
\text { Obreros Rurales y } \\
\text { Agroindustriales } \\
\text { (SUDORA) } \\
\text { Organización de } \\
\text { Obreros Rurales } \\
\text { (OSDOR) } \\
\text { Sindicato de Frutas y } \\
\text { Verduras de Salto } \\
\text { (SOFYV) } \\
\text { Sindicatos de Sandupay } \\
\text { Sindicato Único de } \\
\text { Asalariados Rurales y } \\
\text { Afines (SUARA) } \\
\text { Sindicato de Obreros } \\
\text { Rurales de Salus } \\
\text { (SORS) } \\
\text { SOR - citrus } \\
\text { Sindicato único de } \\
\text { Asalariados Rurales de } \\
\text { Paysandú (SUDOR) }\end{array}$ & $\begin{array}{c}\text { Sindicato de Obreros } \\
\text { Rurales y Destajistas de } \\
\text { San José (SORYDESA) } \\
\text { Sindicato Único de } \\
\text { Obreros Rurales y } \\
\text { Agroindustriales } \\
\text { (SUDORA) } \\
\text { Organización de } \\
\text { Obreros Rurales } \\
\text { (OSDOR) } \\
\text { Unión de Trabajadores } \\
\text { Rurales y } \\
\text { Agroindustriales de } \\
\text { Azucitrus (UTRIA) } \\
\text { Sindicato de } \\
\text { Trabajadores Citrícolas } \\
\text { y Afines (SITRACITA) } \\
\text { Sindicato de } \\
\text { Trabajadores Hortícolas } \\
\text { (STH) } \\
\text { Unión de Trabajadores } \\
\text { Rurales asalariados } \\
\text { del Sur del País } \\
\text { (UTRASURPA) } \\
\text { Movimiento Sindical de } \\
\text { Trabajadores de granja } \\
\text { Unión de Trabajadores } \\
\text { Agrícolas de Belén } \\
\text { (UTABE) } \\
\text { Sindicato de } \\
\text { Trabajadores de los } \\
\text { Arándanos y Afines } \\
\text { (SITRAA) } \\
\end{array}$ \\
\hline Vid & & $\begin{array}{l}\text { Sindicato de Obreros } \\
\text { de Calvinor (SOCAL) } \\
\text { Asociación de } \\
\text { Empleados de los } \\
\text { Viñedos de Villa del } \\
\text { Carmen (AEVIC) } \\
\text { Sindicato de los } \\
\text { Viñedos Faraut }\end{array}$ & $\begin{array}{l}\text { Sindicato de Obreros de } \\
\text { Calvinor (SOCAL) } \\
\text { Sindicato Obrero Viñas } \\
\text { de San Juan } \\
\text { (SOVISAN) } \\
\text { Unión Establecimientos } \\
\text { Juanicó (UTEJ) }\end{array}$ \\
\hline $\begin{array}{l}\text { Ganadería y } \\
\text { agricultura }\end{array}$ & $\begin{array}{c}\text { Sindicato Obrero } \\
\text { Agrario de Salto } \\
\text { Sindicato Agrario de } \\
\text { San Javier } \\
\text { Sindicato de Obreros } \\
\text { de Oficios Varios de } \\
\text { Nuevo Berlin }\end{array}$ & & $\begin{array}{c}\text { Sindicato de } \\
\text { Trabajadores Rurales } \\
\text { (SITRA) } \\
\text { Sindicato de Peones de } \\
\text { Estancias (SIPES) }\end{array}$ \\
\hline Tambos & $\begin{array}{l}\text { Sindicato de Peones de } \\
\text { Tambo de Mendoza } \\
\text { Sindicato Único de } \\
\text { Peones de Tambo } \\
\text { (SUPT) }\end{array}$ & $\begin{array}{l}\text { Sindicato Único de } \\
\text { Peones de Tambo } \\
\text { (SUPT) }\end{array}$ & $\begin{array}{l}\text { Sindicato Único de } \\
\text { Trabajadores de } \\
\text { Tambos y Afines } \\
\text { (SUTTA) }\end{array}$ \\
\hline $\begin{array}{l}\text { Organización } \\
\text { Nacional }\end{array}$ & $\begin{array}{l}\text { Federación Nacional de } \\
\text { Trabajadores Rurales } \\
\text { del Uruguay (FRTR) }\end{array}$ & $\begin{array}{c}\text { Federación Nacional de } \\
\text { Asalariados Rurales } \\
\text { (FENARU) }\end{array}$ & $\begin{array}{c}\text { Unión Nacional de } \\
\text { Asalariados, } \\
\text { Trabajadores Rurales y } \\
\text { Afines (UNATRA) }\end{array}$ \\
\hline
\end{tabular}

Elaboración propia con base en González Sierra (1994), Latorre (1991), Mascheroni (2011), Juncal et al. (2015) Se consideraron aquellos sindicatos que registran algún tipo de actividad en el periodo, aunque no fuera de forma estable. 


\section{Notas}

1 En este trabajo se utiliza el término de trabajador rural como sinónimo de asalariado agrario, que es el sujeto que se estudia efectivamente en este artículo.

2 Esta situación es similar a la que se observa en la región, especialmente para el caso de Argentina (Aparicio, Ortiz y Tadeo, 2008; Rau, 2009; Villulla, 2010; Crespo, 2015; Neiman, 2016).

3 En promedio hay menos de 3 trabajadores por explotación agropecuaria. Esto equivale a más de 100 hectáreas por trabajador permanente y en la ganadería a más de 300 (CGA 1970, 1980, 1990 y 2000).

4 En el año 1870 se funda la Sociedad Tipográfica Montevideana, reconocida como la primera organización formada para la defensa de los derechos de los trabajadores. A partir de ese año, se conforman varias sociedades de socorro mutuo.

5 Golpe conservador del presidente Gabriel Terra (1933 -1938) del Partido Colorado, apoyado por el Partido Nacional Herrerista y las principales cámaras empresariales del país.

6 Los consejos de salarios son órganos de integración tripartita (Estado, empresarios y trabajadores) que tienen como objetivo principal la negociación de los salarios y condiciones de trabajo por rama de actividad (Mascheroni, 2011).

7 La Administración Nacional de Combustibles Alcohol y Portland (ANCAP), creada en 1931, es un ente estatal encargado de explotar y administrar el monopolio del alcohol y carburante nacional y de importar, rectificar y vender petróleo y sus derivados y de fabricar portland.

8 Movimiento político de izquierda que tuvo una etapa de guerrilla urbana en los años 1960 y principios de los 1970.

9 Ya desde la Federación Obrera Regional Uruguaya (1905), primera central obrera que unificó a trabajadores, se mostró la solidaridad del movimiento obrero urbano con los trabajadores rurales, denunciando las condiciones de trabajo y los bajos salarios en el campo. Años más tarde, la Unión General de Trabajadores (1942) se propuso la tarea de organización de los trabajadores rurales. Colaboró en la fundación y sostenimiento de varios sindicatos rurales. Posteriormente, la Central de Trabajadores del Uruguay (1961) da un fuerte dinamismo al debate en torno a la problemática agraria y los trabajadores rurales. En 1961, conjuntamente con la FOL y la SUTP, organiza el Primer Encuentro Nacional de Asalariados del Campo. La plataforma reivindicativa de la CTU del Primer (1963) y Segundo (1966) Congreso Nacional de la central incluyó varias de las demandas de los asalariados rurales: extensión de los consejos de salarios, limitación de la jornada y descanso semanal, seguro de paro, modificación del Estatuto del Trabajador Rural, derecho de los peones a vivir en el establecimiento con sus familias, reforma agraria. Culminado el proceso de unificación sindical bajo la CNT (fundada el $1^{\circ}$ de octubre de 1966), desde la central sindical se continuó bregando por la conformación de una Federación Rural de Trabajadores del campo (creada en 1971), pese al reconocimiento del debilitamiento del movimiento sindical en de los últimos años. La CNT fue la primera central que incluyó en su Mesa Representativa a sindicatos rurales: la SUPT y la UTAA tuvieron lugar en los organismos de dirección de la central, lo cual implicó un reconocimiento de importancia y peso de las organizaciones de los trabajadores rurales. En 1965 varios sindicatos rurales participaron del Congreso del Pueblo. En 1971 se realizó el Primer Encuentro Plenario de Asalariados Rurales de la CNT con una plataforma que incorpora las históricas reivindicaciones de los asalariados rurales (González Sierra, 1994).

10 La FNTR fue fundada por UTAA, SUPT, URDE, CORL (Comité de Obreros Rurales del Litoral), CUTRP, CUTRS, Tabacaleros de Rivera y Tacuarembó. Como observador participó el Sindicato de Frutas y Verduras de Salto.

11 Plenario Intersindical de Trabajadores - Convención Nacional de Trabajadores (PIT-CNT). Es la central sindical única del Uruguay producto de la unificación en el año 1984 del PIT y la CNT.

12 UTAA, SUTRA, SUDORA, UTRIA, SOIMA, Sindicatos de Sandupay, SORYDESA y SUARA. [1] Coalición de partidos de izquierda que ha asumido el Poder Ejecutivo nacional en los periodos 2005-2010, 2010-2015, 2015-2020.

13 Coalición de partidos de izquierda que ha asumido el Poder Ejecutivo nacional en los periodos 2005-2010, 2010-2015, 2015-2020.

14 En el periodo 2003-2013 la cantidad de afiliados al PIT-CNT se triplicó, pasando de 110.000 cotizantes en el año 2003 , a más de 200.000 en 2007, y a 353.000 en 2013. Fuente: https://www.subrayado.com.uy/en-10-anos-se-triplico-la-can tidad-afiliados-al-pit-cnt-n26030 (Consulta: 04.02.2018)

15 Se mantienen las condiciones desventajosas para el acceso al seguro de desempleo en el medio rural.

16 Expresión rural que alude a las cosas que son un invento o ficción, o producto de la imaginación.

17 Los sindicatos rurales tienen grandes dificultades para que sus afiliados realicen los aportes por las dificultades de que los patrones vuelquen lo recaudado a los sindicatos y por la resistencia de algunos asalariados de que su patrones se enteren de su actividad sindical (temor a integrar "listas negras") y, por lo tanto, se afilian pero no quieren que se les realicen los descuentos. Por tanto, la mayoría de los sindicatos rurales tiene un número bajo y muy errático de miembros cotizantes, lo que dificulta su capacidad financiera y consecuentemente de acción. Si bien se da esta baja afiliación en general, es más alta en algunos rubros como caña de azúcar, forestación o citrus. 